\title{
Erratum to: Creep of experimental short fiber-reinforced composite resin
}

Sufyan GAROUSHI',2, Muhammad KALEEM ${ }^{3}$, Akikazu SHINYA'1,4, Pekka K.VALLITTU1 ${ }^{1}$, Julian D. SATTERTHWAITE ${ }^{5}$, David C. WATTS 5 and Lippo V. J. LASSILA ${ }^{1}$

Erratum to: Dental Materials Journal 2012; 31(5): 737-741

doi:10.4012/dmj.2011-247 JOI JST.JSTAGE/dmj/2011-247

Authors would like to correct the affiliation of second author.

The author list should be corrected as follows.

${ }^{1}$ Department of Biomaterials Science and BioCity Turku Biomaterials Research Program, Institute of Dentistry, University of Turku, Lemminkäisenkatu 2, Fl-20520 Turku, Finland

${ }^{2}$ Department of Restorative Dentistry \& Periodontology, Institute of Dentistry, Libyan International Medical University, Benghazi, Libya

${ }^{3}$ Science of Dental Materials, Army Medical College, National University of Science and Technology, Rawal Pindi, Pakistan

${ }^{4}$ Department of Crown and Bridge, School of Life Dentistry at Tokyo, The Nippon Dental University, 1-9-20 Fujimi, Chiyoda-ku, Tokyo 102-8159, Japan

${ }^{5}$ Biomaterials Research Group, School of Dentistry, The University of Manchester, Higher Cambridge Street, Manchester M15 6FH, UK 